\title{
Educação para a cidadania: questão colocada pelos movimentos sociais $^{*}$
}

Marlene Ribeiro

Universidade Federal do Rio Grande do Sul

\section{RESUMO}

0 artigo problematiza a relação entre a cidadania e a educação das camadas populares. Tem por objetivo dialogar, no espaço e no tempo, com o conceito de cidadania, buscando averiguar se este possui conteúdo para infundir-se na educação das camadas populares e quais seus limites e possibilidades que precisam ficar claros para dar visibilidade e lugar a novos conceitos e práticas. Para alcançar tal objetivo os conceitos de cidadania e de educação são mergulhados na história e na filosofia, mais propriamente nas condições em que se assenta a constituição de um cidadão, deduzindo-se, a partir daí, a educação necessária a uma tal constituição. As contradições mostram as possibilidades e os limites da educação como via preferencial de acesso à cidadania, e o fato de que os movimentos sociais populares criam novas formas de produzir, de conviver e de se educar. Nesse processo, gestam novos conceitos cujos conteúdos, marcados pelas práticas de cooperação e solidariedade, parecem projetar a emancipação social em sentido mais amplo do que o proposto pelos princípios formais de liberdade e igualdade em que se assenta a cidadania burguesa. Assim, os movimentos sociais populares ampliam também o horizonte da educação para além da cidadania.

\section{Palavras-chave}

Cidadania e educação - Cidadania e movimentos sociais - Educação e participação política.

\footnotetext{
Correspondência:

Marlene Ribeiro

Rua D. Laura, 924, apto. 201

90430-090 - Porto Alegre - RS

e-mail: maribe@adufrgs.ufrgs.br

* Vinculado à pesquisa Experiências Cooperativas no Campo e na Cidade: subsidiando políticas sociais alternativas em trabalho, educação e lazer apoiada pela FAPERGS.
} 


\section{Education for citizenship: the question posed by social movements}

Marlene Ribeiro

Federal University of Rio Grande do Sul

Correspondence:

Marlene Ribeiro

Rua D. Laura, 924, apto. 201

90430-090 - Porto Alegre - RS

e-mail: maribe@adufrgs.ufrgs.br

* This work is linked to a research project entitled Cooperative Experiences in the Countryside and in the City: supporting alternative social policies in labor, education, and leisure, sponsored by FAPERGS.

\begin{abstract}
The article problematizes the relationship between citizenship and the education of the popular classes. It has as its goal to establish a dialogue in space and in time with the concept of citizenship, attempting to verify if the latter concept has contents to contribute to the education of the popular classes, and what are its limits and possibilities that must be made clear in order to give visibility and room to new concepts and practices. To fulfill this goal the concepts of citizenship and education are immersed in history and philosophy or, more specifically, in the conditions for the constitution of a citizen, whose analysis results in the education necessary for such constitution. The contradictions exhibit the possibilities and limits of education as the main road to citizenship, as well as the fact that popular social movements create new forms of producing, living together, and educating themselves. In this process, social movements gestate new concepts whose contents, characterized by practices of cooperation and solidarity, seem to envisage social emancipation in a sense broader than that proposed by the formal principles of freedom and equality upon which the bourgeois citizenship rests. Thus, popular social movements also broaden the horizon of education beyond citizenship.
\end{abstract}

\section{Keywords}

Citizenship and education - Citizenship and social movements Education and political participation. 


\section{Introduzindo a questão}

A cidadania tem sido, via de regra, o horizonte para o qual os movimentos sociais apontam ao reivindicarem uma educação pública de qualidade, que atenda aos interesses das camadas populares. Assim, a educação voltada para a construção de uma cidadania ativa aquela em que os cidadãos efetivamente participam das decisões políticas que os afetam aparece nos movimentos docentes/discentes, nas organizações comunitárias de pais que lutam por escola, nos programas e nas ações de partidos de esquerda, sendo também uma das bandeiras do Movimento dos Trabalhadores Sem-Terra (MST) - sujeito/objeto privilegiados nas minhas investigações sobre a relação entre o trabalho cooperativo e a educação básica. Há também, por parte de muitos filósofos que refletem sobre a constituição do Estado-nação, ao qual está vinculada a noção moderna de cidadania, um reconhecimento de que a educação é um bem que deve estar acessivel a todos os indivíduos, de modo a tornar possíveis as condições para o exercício de uma efetiva cidadania. Se, como diz Canivez (1998, p. 33), “a escola, de fato, institui a cidadania”, as ações e as concepções do povo enquanto sujeito político exigem "uma revisão profunda na relação tradicional entre educação, cidadania e participação política” (Arroyo, 1995, p. 74).

Essa revisão pressupõe uma compreensão do que seja educação. Uma concepção ampliada de educação abrange os processos formativos que se realizam nas práticas sociais relacionadas às diferentes manifestações de convivência humana que ocorrem na vida familiar, no trabalho, no lazer, na participação política e no aprendizado escolar. ${ }^{1}$ A história irá mostrar que a formação humana, não dissociada das atividades que os homens desenvolvem para produzir suas vidas e mundos, torna-se, na modernidade, educação escolar, separada do mundo do trabalho embora determinada pela organização dos processos produtivos (Ribeiro, 1997). Neste texto, estarei refe- rindo-me à educação escolar, apontada, quase que por unanimidade, como uma via para a constituição da cidadania.

É indiscutível a importância que os diferentes movimentos sociais conferem à escola. Da mesma forma, pensadores modernos identificam a educação como um caminho para a conquista de direitos sociais. Assim, no que tange à cidadania, parece haver um consenso de que a sua conquista implica o conhecimento de direitos e deveres por meio de uma sólida educação escolar básica.

A participação em e a assessoria a determinados movimentos sociais (professores indígenas, agricultores familiares, operários e mulheres, no Amazonas; agricultores familiares e adultos analfabetos, no Rio Grande do Sul) têm-me instigado a adotar uma posição metodológica cartesiana de dúvida a respeito da potencialidade da cidadania como horizonte utópico dos movimentos sociais, mormente os populares. ${ }^{2}$ Trazendo a questão para a educação básica, foco principal das minhas preocupações de pesquisa, a dúvida se amplia quando se observa que ela, a educação escolar, tem sido responsabilizada como a via principal de conquista da igualdade de direitos, portanto, da cidadania.

As dúvidas suscitadas pela observação dos rumos tomados por movimentos sociais populares e pela leitura de alguns autores clássicos da filosofia política me instigam a problematizar a bandeira quase consensual da "educação para a cidadania" como horizonte daqueles movimentos. Qual a possibilidade de alcance de uma cidadania concreta para índios, agricultores, desempregados, adultos analfabetos que justifique ser ela encarada como finalidade última da educação escolar para essas

1. Concordo com a concepção de educação do Fórum Nacional em Defesa da Escola Pública. Ver Ribeiro (2000b, p. 191).

2. A necessidade de identificar os movimentos sociais como populares deve-se à concepção, defendida em outra obra, de que há movimentos sociais que se caracterizam como revolucionários, enquanto portadores de mudanças, e há os que são identificados como reacionários, porque resistem à transformação. No caso, penso que os movimentos sociais populares sejam os que lutam por transformações sociais. (Ferraro; Ribeiro, 1999, p. 9) 
pessoas? Indo mais a fundo, pergunto: que limites a cidadania, enquanto uma categoria histórico-filosófica, apresenta em relação à sua aplicação às camadas populares, que são transpostos para a educação? E, se há limites, quais as potencialidades vivas de conquista de uma cidadania ativa, que ainda permitem afirmá-la como perspectiva da escolarização das camadas populares? Esse é um problema para os movimentos sociais populares, os quais precisam ter claras as suas reivindicações para, a partir delas, formular suas estratégias de luta.

Reconheço que a questão é polêmica, porque se move na contracorrente da histórica e não questionada relação entre cidadania e educação. Por isso, a necessidade de mergulhar ambos os conceitos - cidadania e educação nos contextos de onde emergem e nos autores que os fundamentam. Meu objetivo, portanto, não é ampliar a compreensão da cidadania para a sociedade contemporânea, mas experimentar, questionar, dialogar, no espaço e no tempo, com esse conceito. Averiguar se o mesmo faz sentido para as classes populares; quais os seus limites e possibilidades, que precisam ficar claros para dar lugar e visibilidade a novos conceitos e realidades.

\section{Cidadania e educação no mundo grego}

A relação entre cidadania e educação deve ser pesquisada na história e na filosofia, mais propriamente nas condições em que se assenta a constituição de um cidadão, deduzindo-se, a partir daí, a educação necessária a uma tal constituição.

Wolf (1996) pensa a cidadania vinculada à democracia, um sistema de governo experimentado pela primeira vez em Atenas, na Grécia, que cria as condições para a racionalização do pensamento. A democracia grega, segundo o autor, institui uma forma de poder em que os homens ficam entregues a si mesmos e à sua capacidade de decisão, "sem a autoridade de um chefe, a dominação de uma casta ou a irrecusabilidade de um texto sagrado". Contraditoriamente, essa nova forma de governo, que distribui o poder e o delega aos cidadãos, exclui das decisões políticas cerca de 90\% da população.

Para o mundo grego, que inventou a democracia exclusiva para os grandes proprietários de terras, o ser cidadão define-se pela liberdade do indivíduo e pela igualdade entre os pares. 0 aumento da produção e circulação de riquezas propicia o surgimento da democracia, da cidadania e da filosofia, porém é preciso atentar para as bases em que se assentam essas formas de exercer o poder, de participar da liberdade e de produzir o conhecimento. Aqueles gregos que enriquecem como comerciantes e armadores não são iguais àqueles que possuem a propriedade da terra e do conhecimento, de modo que não reúnem os critérios para uma igual participação na formulação das leis (Châtelet; Duhamel; Pisier-Kovehner, 1994). De modo geral, o exercício do trabalho, aí incluídas as práticas médicas, a produção técnica e artesanal e o comércio dos bens produzidos, confisca o tempo para o ócio, fertilizador do conhecimento político e filosófico. Ser livre, portanto, é não exercer um trabalho, uma profissão, um comércio, uma tarefa material que corresponda à satisfação das necessidades próprias da vida. 0 trabalho, para os gregos, é incompatível com o exercício do livre pensar, com a produção de conhecimentos e com a participação política.

A pressão que comerciantes e armadores fazem para participar da vida pública instaura o debate entre filósofos e sofistas sobre a formação do político. Os sofistas são mestres de gramática e oratória que despertam a reação dos setores mais conservadores ao perceberem ameaçada a sua hegemonia. Os sofistas ensinam aos "novos" ricos, já que as portas da Academia lhes são fechadas, uma estratégia do discurso que os permita participar do debate público; filósofos reagem ao trabalho dos novos professores, que põem em questão seu próprio trabalho de formação do político grego. Esse 
confronto adquire importância para apreendermos as condições de produção da cidadania grega e o papel do conhecimento nesse processo. Com os sofistas a educação passa a significar instrução teórica para a formação do político.

Assim, a necessidade de teorizar sobre a educação nasce do conflito entre os que se consideram filósofos, vinculados à aristocracia ou aos "excelentes" (aristoi), e os que são identificados pejorativamente como sofistas, vinculados ao povo (demos). Estes introduzem a instrução intelectual aos filhos dos novosricos, que não têm acesso à Academia, na qual os filósofos realizam a formação associada à produção do conhecimento político-filósofico, restrita aos cidadãos. É uma educação determinada pela classe à qual o indivíduo pertence e pelo papel e função sociais que deve desempenhar. Na base do conflito está a luta entre as classes proprietárias de terras e as classes emergentes para definir quem pode - e para isso deve ser educado - e quem não pode ser cidadão.

Platão, em A República (1975), estabelece uma relação entre a educação e a cidadania. Delineia uma utopia pedagógica cuja realização depende de uma transformação radical do Estado. Nessa sociedade ideal, a educação corresponde ao desenvolvimento de faculdades e virtudes adequadas às funções que os indivíduos exercem e é essa adequação que produz a justiça, com cada um desempenhando, de maneira satisfatória, a função para a qual é mais apto. Aos filósofos, que cultivam a razão, caberia governar a sociedade.

Se Platão tem para a educação e a cidadania modelos ideais, perfeitos e distantes da realidade, Aristóteles pensa a partir das questões concretas e, ao mesmo tempo, produz uma sintese da filosofia de seu tempo. Na sistematização que faz das tradições, em sua procura por definir um modelo grego para a educação, o filósofo exclui os homens livres do exercício dos ofícios, os cidadãos cuja formação deverá ter por finalidade a cultura. Acima da experiên- cia, da arte e da ciência, Aristóteles (1973) destaca a filosofia como a mais alta de todas as ciências, reservada à formação do homem justo, o cidadão. Para Aristóteles (1977), somente o Estado poderá oportunizar o pleno desenvolvimento dos valores morais "uma vez que todos pertencem ao Estado de que cada um é parte". Portanto, a educação tem caráter público.

Essa concepção de liberdade, princípio correlato à igualdade para a cidadania grega, não se estende, portanto, àqueles que trabalham. Já aí observa-se a separação entre o mundo político e o mundo social, como se este não contivesse aquele. Contraditoriamente, a escravidão daqueles que fazem o trabalho para que os homens atenienses, proprietários de terras e de conhecimentos, possam ser livres e iguais, é a condição de produção da cidadania grega. Entretanto, essa escravidão permanece oculta; não chega a tornar-se nem um objeto de análise nem uma questão política (Touchard, 1970).

Portanto, para o mundo ateniense, a cidadania é uma relação que se estabelece entre homens livres do trabalho - proprietários de terras e de conhecimentos e, por essas características, iguais entre si - com a Cidade-Estado, onde exercem a função de comandar, ao fazer parte do governo, ao mesmo tempo em que obedecem às suas leis. 0 político grego ou o cidadão é aquele que, por nascimento e fortuna, é um homem livre e tem o direito de participar das assembléias e dos debates na ágora. Assim, para os gregos, a essência do homem é tanto a de ser racional quanto a de ser cidadão e homem livre, cuja virtude (areté) consiste no justo exercício dessa cidadania. Por conseguinte, o ideal da educação grega é formar, no homem das classes dirigentes, o político com a capacidade de governar a cidade e de se fazer obedecer pelas demais classes (Marrou, 1975). As mulheres, os idosos, as crianças, os deficientes, os estrangeiros estão excluídos da natureza do ser cidadão, que é participar ativamente da vida pública. Como 
pensavam e se educavam homens e mulheres excluídos da definição e da prática da cidadania? Como universalizar um conceito de cidadania referência para a educação - que tem como conteúdo uma minoria, constituída pelos homens livres, adultos e letrados, que deixa de fora a maioria, constituída de outros homens, mulheres, escravos, trabalhadores e soldados? Poderá esse conceito grego de cidadania situar-se como horizonte da educação reivindicada pelos movimentos sociais populares?

\section{Cidadania e educação no mundo moderno}

A questão da cidadania é enfocada sob um outro ângulo pelos filósofos que pensam a constituição do Estado moderno. A igualdade e a liberdade, como direitos reivindicados pela burguesia que disputa o espaço público com a nobreza e o clero, a centralização do poder e a soberania são as questões definidoras do Estado nacional, no qual está compreendida a cidadania moderna. Pensadores explicam o Estado como uma sociedade artificial, decorrente de uma convenção entre os homens que, segundo Hobbes (1992), buscam a paz e a segurança da propriedade. "A conservação da propriedade”, enquanto produto do trabalho, "seria o fim maior e principal para os homens unirem-se em sociedades políticas" (Locke, 1973). A convenção que criou o dinheiro permitiu que alguns homens, proprietários apenas de seu trabalho, pudessem apropriar-se, também, do trabalho de outros homens, subordinando-os (Locke, 1998). Como esses filósofos, pensa Rousseau (1973a; 1973b) que a sociedade política seja produto de uma convenção. Diferente deles, todavia, acredita que o Estado gera condições de sociabilidade que tornam o homem fraco, medroso, subserviente, debilitado de sua força e coragem naturais.

A cidadania moderna, vinculada ao Estado-nação e à afirmação da burguesia enquanto classe, guarda, em sua definição, elementos comuns e, ao mesmo tempo, diferentes aos encontrados na cidadania grega. 0 cidadão, tanto o grego clássico como o europeu moderno, é um indivíduo masculino, dotado de razão e proprietário. No caso grego, a razão está associada à propriedade da terra, ao ócio, ao exercício do conhecimento filosófico e à ação política. No caso da cidadania moderna, a razão está em franca hostilidade com a meta-física, porque associada ao comércio e ao nascimento das ciências físico-naturais; a proprie-dade é, além da terra, a dos meios de produção. Nos dois casos, a cidadania qualifica classes que estão no poder (Atenas) ou que aspiram ao poder (burguesia européia). A diferença está em que a filosofia, cujo discurso dá sustentação à cidadania grega, não proble-matiza a propriedade - inclusive a dos escravos - vista como um bem natural daquele que tem o dom da inteligência e a liberdade das mãos para melhor governar e pensar. No caso da cidadania moderna, os pensadores que refletem sobre o Estado-nação, no qual se encontram os fundamentos dessa cidadania, percebem a propriedade como resultante do trabalho humano. 0 trabalho significa, portanto, a ruptura com o estado de natureza e o fundamento do princípio da propriedade, que dá ao homem burguês a justificativa moral e legal para preservá-la e defendê-la. Entretanto, associado à idéia de uma racionalidade que determina o uso dos meios naturais em função dos fins orientados para a produtividade e o progresso, o trabalho, ao romper com o estado de natureza, pode justificar, também, a expropriação da terra, a subordinação dos camponeses, a escravidão dos negros e até o extermínio daqueles que não a fazem produzir por "métodos racionais", como os povos indígenas.

Como pensar que essas populações indios, negros, agricultores, analfabetos - hoje organizados em movimentos sociais, alijados da cidadania desde a sua origem grega, queiram alcançá-la? Se, tanto a cidadania grega como a cidadania moderna não estão alicerçadas na educação escolar mas na propriedade privada, como pretender que a escola seja a ponte para a conquista da cidadania? 
No período histórico caracterizado como lluminismo, desenvolve-se uma pedagogia política que põe em pauta a luta por uma escola pública, leiga, gratuita, de caráter científico, pontos estes que aparecem nos discursos do período revolucionário francês, especialmente em La Chalotais, Condorcet e Lepelletier (Lopes, 1981; Luzuriaga, 1959). Nos discursos dos defensores de uma escola pública elementar é possivel identificar o vínculo com a formação dos Estados nacionais, em que está implícita a necessidade de transferir o domínio da Igreja sobre os fiéis para a dominação do Estado sobre os cidadãos (Ribeiro, 1997).

A dualidade marca o projeto iluminista, que justifica a existência de dois projetos diferentes de escola, um para o povo e outro para as classes dirigentes, tanto pelo princípio da liberdade individual - que não admite uma educação padronizada - quanto pela desigualdade natural das faculdades humanas, que respalda a classificação dos alunos em mais capazes e em menos capazes, justificando a existência de ricos e pobres. À medida que a burguesia vai se consolidando como classe, a pedagogia política, que no discurso aparecia como defesa de uma escola livre, leiga, gratuita, para todos, vai se transformando na defesa de uma escola adequada para atender às diferenças individuais ou àqueles que têm méritos (Luzuriaga, 1959). 0 caráter político da afirmação do projeto pedagógico iluminista - a formação do cidadão - é então esvaziado, adquirindo um significado psicologizante, justificador das desigualdades sociais (Machado, 1989).

A confiança no poder da razão suscita em alguns filósofos a necessidade de organizar o conhecimento sob forma de enciclopédia. 0 movimento enciclopedista é também estimulador da difusão do conhecimento sistematizado como possibilidade de acesso às luzes da razão e como antídoto às crenças e aos preconceitos. Entretanto, a escola que ele propõe destina-se a desenvolver as capacidades intelectuais da elite, ao afirmar, em seu verbete sobre a educação, que
(...) é evidente que para cada ordem de cidadãos num Estado há um tipo de educação próprio: educação para os filhos dos soberanos, educação para os filhos dos grandes, para os filhos dos magistrados, etc...educação para as crianças dos campos (...). (Enciclopédia, apud. Manacorda, 1989, p. 242)

Rousseau, um pensador do lluminismo, propõe uma nova ordem baseada no contrato social, porém que seja justa, buscando uma solução que equilibre as inclinações individuais com o que chama de vontade geral. Nisso consiste a sua originalidade em relação aos demais pensadores que vêem o contrato social como gênese da sociedade política (Chevalier, 1980). Sendo um liberal, Rousseau pensa a sociedade como uma agregação de indivíduos e a educação como necessária à formação do cidadão livre e, ao mesmo tempo, sujeito às leis. Em decorrência, seu ideal educativo não é formar o jovem em contato com a natureza para que este permaneça segregado do mundo; ao contrário, preocupa-se com que o indivíduo esteja preparado para participar da vida política. Sua biografia mostra a incoerência de suas práticas com suas idéias; idéias que viriam a influenciar as concepções de infância que se forjaram na modernidade (Eby, 1962).

A consolidação do Estado liberal vai produzindo discursos que se afastam daquela análise que afirma o trabalho como origem e fundamento da propriedade. Tais discursos procuram redefinir os princípios de liberdade e igualdade - fundamentos da cidadania - em moldes mais adequados à ordem político-econômica burguesa. A questão é: como conciliar a liberdade do indivíduo com a igualdade dos cidadãos perante a lei?

Rousseau propõe uma democracia direta, não representativa, em que o cidadão intervenha diretamente nos processos políticodecisórios que são de seu interesse. Em Kant, 
essa mesma questão é formulada de um modo diferente, levando o debate para uma nova direção. A preocupação do filósofo alemão é explicar a contradição entre a liberdade do indivíduo e a vontade autônoma para formular uma moral que, ao mesmo tempo, responda pela liberdade de cada um e pela igualdade dos cidadãos que vivem em sociedade. Sob a influência da religião reformada, Kant opta por uma solução abstrata que preserve a afirmação da autonomia e da liberdade, salvando a coerência de seu sistema de pensamento. Trabalhando com as idéias de contrato social baseado na democracia direta - de Rousseau - e de um soberano que tome a si o encargo de garantir a paz e a segurança ameaçadas pelo egoísmo natural do homem - de Hobbes -, Kant propõe uma síntese que desarma o potencial revolucionário da cidadania de Rousseau, "em que as relações de poder são legitimadas unicamente através de uma participação democrática dos cidadãos sem mediações nem interpretações" (Carracedo, 1988, p. 67).

Em dois textos menos conhecidos, Kant (1995a, 1995b) define com muita clareza os elementos constituintes da cidadania moderna a partir dos princípios em que se assenta o Estado civil: "1. a liberdade de cada membro da sociedade como homem; 2 . a igualdade deste com os outros, como súdito; 3 . a independência de cada membro de uma comunidade como cidadão" (Kant, 1995b, p. 75). A liberdade, exercida segundo as leis, permite a igualdade, que se reflete na possibilidade de, com os próprios méritos, ascender socialmente; a igualdade, por sua vez, supõe que cada um tenha as condições necessárias para desenvolver suas capacidades. Kant não admite privilégios de nascimento. Daí a importância da educação por meio da qual o homem se realiza como tal, tanto porque lhe dá condições de ascensão social quanto porque é pelo conhecimento que o homem supera a minoridade em que se encontra mergulhado, fonte de preconceitos e da ignorância (Kant, 1995a, 1996). A igualdade dos homens perante a lei não conflita com as desigualdades sociais porque pobres, mulheres e crianças dependem naturalmente dos ricos, dos maridos e dos pais. Começam, então, a definir-se os limites dos princípios de liberdade e de igualdade em que está alicerçada a cidadania burguesa, limites estes que irão definir a educação básica destinada às camadas populares.

Até aqui os princípios formais de liberdade e igualdade, na visão de Kant, abarcam toda a população na condição de súditos, concretizando-se na relação com o chefe de Estado e na obrigatoriedade de submeter-se às leis civis. Ao mesmo tempo, esses princípios deixam abertura a um terceiro - o de independência -, no qual se encontra o efetivo conteúdo da cidadania kantiana, que se define pelo gênero masculino, pela raça branca, pela cultura européia e pela propriedade privada do conhecimento e dos meios de produção (terras e indústrias). Assim, é no princípio de independência que as restrições à participação política, campo peculiar ao exercício da cidadania, são postas com maior clareza, no pensamento de Kant. A independência trata do princípio relativo ao cidadão como legislador, possibilitando estabelecer uma diferença entre o cidadão do Estado, aquele que está apto a participar das leis porque tem independência, tem a posse do conhecimento, a propriedade da terra e/ou exerce uma profissão liberal, e o cidadão burguês, habitante da cidade. 0 poder deverá ser exercido, portanto, pela representatividade daqueles que estão aptos a votar, isto é, por aqueles que gozam da independência econômica, política e cognitiva.

0 que Kant propõe para a educação deriva-se de suas concepções filosóficas e políticas. Ele afirma que "o homem não pode chegar a ser homem a não ser por intermédio da educação. Ele não é mais do que aquilo que a educação faz dele" (Kant, 1996a, p. 73). Educa-se para o exercício da razão por meio da disciplina, aspecto negativo da formação, no qual o homem aprende a dominar seus instintos, e por meio da instrução, aspecto positivo, 
no qual adquire cultura (Kant, 1996b).

Avançando na configuração da cidadania burguesa, Hegel (1990) separa a sociedade política, ou o Estado, da sociedade civil, que comporta: a) o sistema de carências mediadas pelo trabalho; b) a liberdade implícita nesse sistema (defesa da propriedade e da justiça); c) a prevenção dos problemas ou conflitos resultantes da relação entre o sistema de carências e a realidade da liberdade. Para Hegel, o objetivo da sociedade civil é a realização do cidadão - indivíduo ou pessoa privada - que tem como fim seu próprio interesse, o qual se realiza através do interesse universal. No plano das carências e de suas satisfações, o objetivo, na “(...) sociedade civil em geral, é o cidadão, e aqui, do ponto de vista da carência (...) é a representação concreta a que se chama homem" (Hegel, 1990, p. 185). 0 filósofo identifica três classes sociais: a substancial, que detém a propriedade da terra e das riquezas nela produzidas; a industrial, proprietária das indústrias e que se ocupa da transformação dos produtos naturais; e a classe universal, voltada para os interesses gerais da sociedade. Hegel localiza a classe universal, ou os funcionários de carreira do Estado, na classe média, na qual residiria a inteligência culta e a consciência jurídica (Lefebvre, 1986). Semelhante à cidadania pensada por Kant, a cidadania hegeliana não abarca as mulheres, porque estas estão em situação de dependência em relação aos maridos, nem os pobres, porque estes estão sujeitos às carências materiais. Hegel admite a existência e até o aumento do número de pobres na Alemanha, mas não aponta solução para o caso, uma vez que, em sua opinião, a esmola desestimula o pobre a procurar trabalho e a oferta de trabalho para todos poderá ser prejudicial à economia, uma vez que podem ser fabricados mais produtos do que o mercado tem a capacidade de comercializar. Reconhecendo que a invenção de novas máquinas poderá excluir homens, Hegel
(1990, p. 188) julga que os pobres devam ser jogados ao seu próprio destino. É lícito deduzir que, para esses pobres, não haja nem cidadania nem educação...

Hegel pensa em uma formação voltada para a vida pública, mais especificamente, para o serviço do Estado. Nesse sentido, a função da escola deve ser compreendida em relação a sua concepção de Estado sustentado por uma classe média constituída de funcionários competentes e por uma classe política situada acima das demais classes, com funções de governo. É, portanto, tarefa da escola preparar os indivíduos para serem membros desse Estado.

Diferente do animal, que não precisa de nenhum tipo de formação para realizar sua "animalidade", o homem, como ser de razão, não nasce pronto, precisa ser educado a fim de harmonizar sua dupla face de natureza e de razão, de modo que esta última prevaleça. 0 objetivo da educação é, portanto, superar o estado de natureza, rompendo com seu imediatismo para atingir o que seria uma segunda natureza, de caráter espiritual. A disciplina é indispensável para superar o estado de natureza ou a imediaticidade das necessidades humanas (Hegel, 1991).

0 Estado liberal pretende-se instrumento de aplicação das condições de liberdade e de igualdade para o progresso da razão. Tem como horizonte a democracia, mas não pode ser democrático porque é resultado da reivindicação de uma classe, a burguesia. A liberdade e a igualdade, que estão na origem do Estado e da cidadania liberais, referem-se basicamente à eliminação dos privilégios estamentais e dos entraves para o comércio. Por trás da idéia de assegurar a ordem, a segurança e a paz estão os conflitos da burguesia com a nobreza e o clero pelo direito à manutenção da propriedade privada. Como ficam então a liberdade e a igualdade quando a nova sociedade que se organiza não garante condições de 
materialidade para que estes princípios sejam estendidos a todos? Como fica a educação para a cidadania se a maioria das pessoas não consegue alcançar os requisitos para tornarem-se cidadãs?

De modo geral, há uma concordância entre os autores analisados em pôr os princípios de igualdade e de liberdade como alicerces do pacto social que dá origem ao Estado civil; em assumir a democracia como a melhor forma de governo e, como conseqüência, em defender o exercício da cidadania por meio da participação política do cidadão, seja na elaboração das leis, seja na eleição dos governantes, seja no cumprimento dos deveres para com o Estado. Retomando a argumentação que fundamenta esses princípios, no entanto, e que toma como base concreta um determinado cidadão, que é masculino, branco, europeu, proprietário de terras, de meios de produção e de conhecimento, percebemos tais princípios como abstratos. Os clássicos do pensamento liberal reconfiguram o poder político de modo a justificar o ingresso da burguesia nas instâncias legislativa, executiva e judiciária, mas mantêm excluída desse poder político a maioria da população, ou seja, as mulheres e os trabalhadores urbanos e rurais, estes já excluídos econômica e socialmente. A exclusão das etnias negras e indígenas, entre outras, nem sequer é problematizada, uma vez que a noção de cidadania é filiada a um conceito de razão iluminista e evolucionista, que carateriza africanos e índios como "povos primitivos". Se a categoria gênero humano é produzida no processo de colonização das Américas (ÁlvarezUría, 1998), como pensar que índios, sobre os quais pairava a dúvida se seriam ou não humanos, pudessem vir a ser cidadãos?

0 que torna aceitável e coerente a argumentação que dá conteúdo ao discurso burguês sobre o Estado, a democracia e a cidadania, e o legitima, é a separação entre a realidade política e as realidades econômica e social, porque nestas a materialização das desigualdades é incontestável. lsolada da base material e social, a instância política assenta-se em uma razão imune à sensibilidade, que considera justa a independência kantiana como critério de participação democrática, mas não admite a compaixão e a solidariedade com os excluídos da cidadania, os pobres e os desempregados, por exemplo, que, de acordo com Hegel, deveriam ser abandonados à sua própria sorte.

Uma análise sobre o processo de construção da cidadania burguesa, mesmo que superficial, pode auxiliar na compreensão da educação a ela vinculada. A cidadania significa ter as luzes do conhecimento, da leitura, da escrita e da matemática; exclui, portanto, aqueles que não têm acesso ao conhecimento escolar ou são sujeitos de culturas e/ou raças identificadas como "primitivas" porque estão mais próximas ao estado de natureza. Em ambos os casos, os iletrados e os chamados "primitivos", ou "irracionais”, são considerados, no processo evolutivo da humanidade, em situação inferior ao estágio atingido pela racionalidade ocidental "civilizada".

A educação é pressuposto para o alcance da cidadania burguesa, que se assenta sobre os princípios de liberdade e igualdade. Em base a estes principios, a sociedade deveria oferecer, principalmente através da educação básica, condições igualitárias para que os indivíduos tivessem acesso ao exercício de uma cidadania ativa. Contraditando com este discurso, o Estado burguês cria artifícios que inviabilizam a universalização de uma educação pública articulada aos interesses dos segmentos sociais e culturais tradicionalmente excluídos do conceito e das práticas que implicam a cidadania.

\section{Cidadania e educação no Estado social}

No contexto de criação de diferentes modalidades de Estado social, no pós-guerra, a cidadania esteve associada a direitos sociais, principalmente os de proteção ao trabalho. 0 período em que vigorou o Estado 
social estendeu-se por cerca de 30 anos (1945-1973), ampliando-se o conteúdo das políticas de bem-estar e o número de pessoas por elas atingido. A dissolução da URSS, associada ao que alguns autores chamam de crise fiscal (Bobbio et al., 1995), permitiu que o pensamento neoliberal se tornasse hegemônico e, com a justificativa de anular a intervenção do Estado na economia, eliminasse as bases do Estado social, principalmente os direitos relacionados ao trabalho. A questão da cidadania apresenta-se, assim, com muita ênfase, quando direitos sociais, de responsabilidade do Estado, são transformados em direitos individuais e transferidos a o consumidor, que passa a comprar, no mercado, bens como saúde e educação, transformados em mercadorias (Ribeiro; Ferraro; Verones, 2001). Nesse caso, fazem sentido as lutas sociais pela retomada dos direitos de cidadania? Ou melhor, a cidadania é capaz de potencializar as lutas por direitos sociais, entre estes o de educação, em um contexto de desemprego estrutural e tecnológico e de destruição do Estado social?

0 Estado social é uma resposta do capital tanto às suas próprias necessidades quanto à ameaça proveniente do avanço dos movimentos revolucionários. ${ }^{3}$ De um lado, repassa ao conjunto da sociedade, representado pelo Estado, os altos custos para o financiamento das condições gerais de produção; de outro, contempla os sindicatos - por meio de pactos com eles firmados -, a lgreja católica, o Estado e o empresariado, com direitos de proteção ao trabalho, financiamento da educação, da saúde, etc. (Offe, 1991), compreendidos como direitos de cidadania. Portanto, repassa também ao conjunto da sociedade parte dos custos com a reprodução da força de trabalho, que assumem a figura de direitos sociais financiados pelo Estado. ${ }^{4}$ A democratização da educação pública que, no periodo dos Anos Dourados (Hobsbawm, 1995), obteve consideráveis avanços, principalmente nos países europeus e da América do Norte (Santos, 1994), pode ser interpretada dentro desse processo contraditório que contempla os interesses dos trabalhadores por ampliação dos direitos sociais, ou de cidadania, e os interesses do sistema capitalista, no que tange à produção e ao consumo de massa e ao custeio da reprodução da força de trabalho.

\section{Cidadania regulada e educação no Brasil}

No Brasil, a regulamentação das relações de trabalho, durante o Estado Novo (anos 1930-1940), que Santos (1987) chama de cidadania regulada, constituiu-se juntamente com a ampliação da rede pública de educação primária, visando disciplinar operários para as fábricas que se expandiam. A cidadania regulada ocorre num período de ampliação dos postos de trabalho e materializa-se no exercício de uma profissão que, por sua vez, define a formação profissional que se irá fazer nas escolas técnicas e no Sistema "S". Ficam excluídos dessa cidadania os agricultores, os desempregados e os sem-profissão, na maioria negros.

A atual desregulamentação das relações de trabalho imposta pelo Estado neoliberal, aliada ao desemprego, amplia o número daqueles que não têm acesso aos direitos conferidos pela cidadania regulada. Essa desregulamentação atinge as profissões que tinham suas atribuições definidas e salários registrados na Cartei-

3. A necessidade do Estado social (ou do Bem-Estar, ou da Providência),
para responder à questão do desemprego e dos movimentos operários, é
reconhecida por Keynes, (1996), Polanyi (2000) e Galbraith (1998), pen-
sadores liberais. Uma interpretação do desmantelamento do Estado social
pelo neoliberalismo, tendo por cenário a queda do Muro de Berlim e o
esfacelamento da URSS, remete à organização daquele Estado em face da
ameaça proveniente dos movimentos revolucionários, no início do século
XX. Essa leitura é feita por alguns autores na obra organizada por Blackburn
(1993).
4. 0 Brasil não chegou a ter um autêntico Estado social, apenas uma
legislação regulamentadora das relações de trabalho (Consolidação das
Leis do Trabalho). Santos (1987) afirma que o Estado brasileiro criou uma
cidadania regulada que incluía apenas os trabalhadores vinculados ao
mercado formal de trabalho.
5. Sobre Educação Profissional e Sistema "S", ver Cunha (2000, v. 3). 
ra de Trabalho, substituidas agora pelas "competências" individuais que as escolas técnicas têm dificuldade para definir em seus currículos. ${ }^{6}$ Sabe-se, em todo o caso, já não ser mais a força coletiva dos sindicatos quem as define, mas a relação patrão-empregado que, em um contexto de desemprego, deixa o trabalhador refém do empregador.

A força dos movimentos do campo fez com que os agricultores familiares fossem incluídos na cidadania regulada pela Constituição "Cidadã" de 1988, que os integrou ao sistema produtivo como trabalhadores rurais e ao sistema previdenciário como cidadãos portadores de direitos. Não foi, portanto, a escola rural, que historicamente tem negado seu estatuto de sujeitos produtores de bens e de saberes, que lhes conferiu ingresso na cidadania regulada, mas a sua capacidade de organização e de luta pela terra e por direitos sociais.

A educação é reconhecida, pela maior parte dos autores que tratam da cidadania, como um direito essencial enquanto propiciador das condições necessárias à inclusão no espaço público, ou seja, no campo da participação política. 0 direito ao acesso à educação para todos os cidadãos traduz a afirmação de um bem comum à comunidade política e ao compartilhamento, por parte de seus membros, do conhecimento como um valor. Porém, a inexistência da possibilidade de realização do direito à educação, ou a insuficiência de condições para o seu exercício, implica também que a igualdade de direitos e deveres de cidadania está anulada ou prejudicada. Homens e mulheres não nascem com o conhecimento das leis, dos direitos e dos deveres da cidadania, o que pressupõe um longo processo de socialização e de escolarização. Se esse processo não se efetiva, automaticamente, está sendo negado um dos direitos essenciais da cidadania. Portanto, a educação pública é um dever básico do Estado para com os seus concidadãos. Se o acesso igual à educação é concebido como uma das condições essenciais da cidadania, então o Estado de direito o deve instituir sob pena de não garantir a igualdade dentro do próprio corpo político (Gaille, 1998).

No Brasil, com o esvaziamento da cidadania regulada, que caminha paralelo a um descompromisso cada vez maior do Estado com a educação pública (Ribeiro, 2000a), perguntase: quais as possibilidades e limites para a cidadania das camadas populares na sociedade brasileira contemporânea?

\section{Potencialidades e limites de uma educação para a cidadania}

Retomando a questão inicial, em relação aos movimentos sociais populares e sobre a potencialidade do conceito de cidadania e a sua propriedade como horizonte da educação pública, creio que há possibilidades e limites.

As possibilidades podem ser visualizadas nas relações sociais contraditórias em que se produz/reproduz a cidadania como síntese de lutas entre classes sociais com interesses e projetos antagônicos. Assim, se o neoliberalismo confisca os direitos conquistados pelos movimentos sociais, os partidos de esquerda, no Brasil, têm reafirmado esses direitos sociais como prioridade em seus governos estaduais e municipais. Principalmente o direito à educação básica, concebida como instrumento essencial para a conquista da cidadania, tem recebido atenção privilegiada nos programas e administrações de partidos de esquerda. ${ }^{7}$ Isso mostra que a cidadania é um conceito contraditório, dinâmico, cujo conteúdo restringe-se ou amplia-se conforme a força dos movimentos socais que a reivindicam. Os limites podem, assim, ser alargados pela participação dos sujeitos interessados na conquista de direi-

6. Sobre a introdução do ensino profissional por competências, ver Ramos (2001).

7. Na educação, tem-se destacado o programa Bolsa-Escola e as experiências da Escola-Candanga, de Brasília/DF; Escola-Plural, de Belo Horizonte/MG; Escola-Cidadã, de Porto Alegre/RS entre outras. A experiência de Porto Alegre, pela bandeira adotada — cidadã — mereceria uma análise mais aprofundada não desenvolvida aqui para não me distanciar dos propósitos colocados para este texto. Ver Arroyo (2000, p. 9). 
tos sociais, entre os quais, o da educação escolar.

Mesmo com o alargamento possível do campo de participação política e dos direitos, alcançado principalmente por meio das lutas empreendidas pelos movimentos sociais, a cidadania não abarca a totalidade dos segmentos sociais constituintes das classes subalternas, uma vez que essas são heterogêneas. 0 isolamento do indivíduo, sujeito da cidadania, não se coaduna com os movimentos sociais populares enquanto sujeitos coletivos. A revalorização da cultura do trabalho e da experiência dos agricultores familiares, compreendida nos processos de luta pela reforma agrária, não cabe no conceito de cidadania, cujo conteúdo inclui a civilização por oposição ao mundo rural e à cultura camponesa, ambos considerados arcaicos. Essa mesma questão pode ser levantada tanto no que diz respeito aos movimentos indígenas, que têm por bandeiras a demarcação de terras e a sua autodeterminação enquanto povos, quanto no que diz respeito ao movimento negro e às suas lutas contra a discriminação e pela valorização da cultura afro-brasileira.

0 conceito e a realidade da cidadania, mergulhados na sua compreensão histórico-filosófica, identificam a cidade, a civilização, o discurso, a gramática, a retórica, a escrita, a língua e a cultura dominantes, o conhecimento, a raça branca, a propriedade privada da terra e dos meios de produção como conteúdos indispensáveis a esse conceito e a essa realidade. Seria a educação escolar capaz de conferir tais conteúdos aos movimentos sociais populares quando alguns desses conteúdos são de natureza incompatível com determinadas populações-sujeitos de movimentos sociais populares?

A educação tem sido uma preocupação fundamental dos governos populares, todavia ela esbarra nas relações que esses governos estabelecem com o governo federal, sujeito às políticas neoliberais determinadas pelos organismos financeiros internacionais, como o Fundo Monetário Internacional e o Banco Mundial. ${ }^{8}$
Com essas políticas, o Estado desloca o custeio da educação infantil e da escola básica públicas para a responsabilidade de municípios e estados, desenvolve políticas de privatização das universidades, estabelece condições e formas de repasse de recursos, intervém na elaboração das leis que regem a educação e exerce um controle rigoroso sobre conteúdos, metodologias e aplicação de recursos por meio do estabelecimento dos Parâmetros Curriculares Nacionais (PCNs) e das "provas objetivas" de avaliação das escolas e dos cursos, do ensino fundamental ao superior (Minto, 1999; Ribeiro, 2000a; 2000b).

\section{Perspectivas de emancipação apresentadas pelos movimentos sociais}

As contradições mostram algumas possibilidades, todavia são muitos os limites inerentes à educação escolar para que ela possa se constituir como via preferencial de acesso à cidadania. Governos populares esbarram na escassez de recursos econômicos e nos instrumentos legais que cerceiam a construção de alternativas. 0 desemprego produzido pelas transformações no trabalho e no Estado, impostas pelo neoliberalismo, elimina, para uma parcela crescente da população, as condições concretas de integração no mercado de trabalho, de conquista de uma identidade social e, portanto, de exercício de uma efetiva cidadania.

Ao largo do Estado, movimentos sociais populares organizam-se e começam a criar alternativas de trabalho e de relações cooperativas para enfrentar o desemprego, alternativas estas muitas vezes cooptadas por empresas e pelo próprio Estado no intuito de reduzir custos com direitos sociais. Como Ferreira (1993, p. 228), penso que "a humanidade não deixa de inventar e de se inventar”. Nesse movimento, em que as camadas populares criam novas for-

8. Ver De Tommasi et al. (Org.). O Banco Mundial e as políticas educacionais. 2. ed. São Paulo: Cortez; PUC/SP; Ação Educativa, 1998. 
mas de produzir, de conviver e de educar-se, gestam-se também novos conceitos, nos quais o conteúdo, marcado pelas práticas de cooperação e de solidariedade, projeta a emancipação social em sentido mais amplo do que o proposto pelos princípios abstratos de liberdade e de igualdade, ampliando-se, assim, o horizonte da educação para além da cidadania burguesa.
Se a filosofia e a história mostram que a cidadania, tanto grega como moderna, não foi desenhada para justificar a participação política de indios, negros, mulheres, trabalhadores rurais e urbanos, por que não imaginar que esses sujeitos, em seus movimentos, possam ser capazes de inventar seus próprios conceitos, suas próprias utopias, suas próprias escolas?

\section{Referências bibliográficas}

ÁLVAREZ-URÍA, Fernando. A conquista do outro: da destruição das índias ao descobrimento do gênero humano. In: LARROSA, Jorge; LARA, Nuria P. de Imagens do Outro. Petrópolis: Vozes, 1998. p. 97 - 114.

ARISTÓTELES. Metafísica. Livro 1. Textos Selecionados. São Paulo: Abril Cultural, 1973. (Os Pensadores). Tratado da Política. Mira-Sintra: Europa-América, 1977.

ARROYO, Miguel G. Educação e exclusão da cidadania. In: BUFFA, Ester et al. Educação e cidadania. Quem educa o cidadão? 5. ed. São Paulo: Cortez, 1995. p. 31-80.

Ofício de mestre: imagens e auto-imagens. Petrópolis: Vozes, 2000.

BLACKBURN, Robin (Org.). Depois da queda: o fracasso do comunismo e o futuro do socialismo. 2. ed. Rio de Janeiro: Paz e Terra, 1993.

BOBBIO, Norberto et al. Dicionário de política. 7. ed. Brasília: UNB, 1995.

CANIVEZ, Patrice. Educar o cidadão. 2. ed. Campinas: Papirus, 1998.

CARRACEDO, José R. El influxo de Rousseau en la filosofia práctica. In: GUIZÁN, Espéranza (Coord.). Esplendor y miséria de la ética kantiana. Barcelona: Anthropos, 1988. p. 29-74.

CHÂTELET, François; DUHAMEL, Olivier; PISIER-KOUCHNER, Evelyne. História das idéias políticas. Rio de Janeiro: Jorge Zahar, 1994.

CUNHA, Luiz A. O Ensino profissional na irradiação do industrialismo. São Paulo: UNESP; Brasília: Flacso, 2000. v.3.

EBY, Frederick. História da educação moderna. Porto Alegre: Globo, 1962.

FERRARO, Alceu R.; RIBEIRO, Marlene. Movimentos sociais: revolução e reação. Pelotas: EDUCAT, 1999.

FERREIRA, Nilda Teves. Cidadania: uma questão para a educação. 3.ed. Rio de Janeiro: Nova Fronteira, 1993.

GAILLE, Marie. Le citoyen. Paris: Flammarion, 1998.

GALBRAITH, John K. 0 engajamento social hoje. Folha de S. Paulo, São Paulo, 20 dez 1998. Caderno Mais, p. 4.

HEGEL, Princípios de filosofia do direito. Lisboa: Guimarães Ed., 1990.

Escritos pedagógicos. México: Fondo de Cultura Económica, 1991.

HOBBES, Thomas. Leviatã ou matéria, forma e poder de um estado eclesiástico e civil. São Paulo: Abril Cultural, 1974. (Os Pensadores). 
Do cidadão. São Paulo: Martins Fontes, 1992.

HOBSBAWM, Eric. Era dos extremos: o breve século XX, 1914-1991. São Paulo: Cia. das Letras, 1995.

KANT, Immanuel. A paz perpétua e outros opúsculos. Lisboa: Edições 70, 1995.

Resposta à pergunta: 0 que é o lluminismo? In: . A paz perpétua e outros opúsculos. Lisboa: Edições 70, 1995a.

. Sobre a expressão corrente: isto pode ser correto na teoria mas nada vale na prática. In: . A paz perpétua e outros opúsculos. Lisboa: Edições 70, 1995b. Réflexions sur l'éducation. Paris: J. Vrin, 1996a. Sobre a pedagogia. Piracicaba: Unimep, 1996b.

KEYNES, John Maynard. A teoria geral do emprego, do juro e da moeda. São Paulo: Nova Cultural, 1996.

LEFEBVRE, Henri. Hegel, Marx, Nietzsche. México: Sieglo Vienteuno, 1986.

LOCKE, John. Segundo tratado sobre o governo: textos selecionados. São Paulo: Abril Cultural, 1973. (Os Pensadores). . Dois tratados sobre o governo. São Paulo: Martins Fontes, 1998.

LOPES, Eliane Marta T. Origens da educação pública. São Paulo: Loyola, 1981.

LUZURIAGA, Lorenzo. História da educação pública. São Paulo: Nacional, 1959.

MACHADO, Lucília R. de S. Politecnia, escola unitária e trabalho. São Paulo: Cortez e Autores Associados, 1989.

MANACORDA, Mário Alighiero. História da educação. São Paulo: Cortez/Autores Associados, 1989.

MARROU, H. I. História da educação na antigüidade. São Paulo: EPU; Brasília:INL, 1975.

MINTO, César Augusto. A educação nos tempos da "Dama de Ferro". Universidade e Sociedade, Brasília, n.18, p. 103-107, mar. 1999.

OFFE, Claus. Trabalho e sociedade: problemas estruturais e perspectivas para o futuro da sociedade do trabalho. Rio de Janeiro: Tempo Brasileiro, 1991. v.2.

PLATÃo, A república. Mira-Sintra: Europa-América, 1975.

POLANYI, Karl. A grande transformação: as origens da nossa época. 2.ed. Rio de Janeiro: Campus, 2000.

RAMOS, Marise N. A pedagogia das competências: autonomia ou adaptação? São Paulo: Cortez, 2001.

RIBEIRO, Marlene; FERRARO, Alceu R.; VERONEZ, Luiz F. Trabalho, educação, lazer: horizontes de cidadania possível. Sociedade em Debate, Pelotas, v. 7, n.2, p. 99-134, ago. 2001.

RIBEIRO, Marlene. Trajetória da educação liberal: alguns traçados. Cadernos de Educação, Pelotas, n. 9, p. 155-184, jul./dez. 1997.

Cidadania: interrogações ao conceito para a compreensão dos movimentos sociais. Caderno de Debates, Porto Alegre, $\mathrm{n}$. 2, p. 43-82, 2001. 2000a.

Panorama da educação básica brasileira: perspectivas para o século xxı. Revista Pedagógica, Chapecó, n.5, p. 27-56, dez.

Formação de professores e escola básica: perspectivas para a pedagogia. Educação e Realidade, Porto Alegre, v. 25, n. 2, p. 179-202, jul/dez. 2002b. 
ROUSSEAU. Do contrato social: textos selecionados. São Paulo: Abril Cultural, 1973a. (Os Pensadores).

Discurso sobre a origem e os fundamentos da desigualdade entre os homens. São Paulo: Abril Cultural, 1973b. (Os Pensadores).

SANTOS, Boaventura de S. Pela mão de Alice: o social e o político na pós-modernidade. 3. ed. Porto: Afrontamento, 1994.

SANTOS, Wanderley G. dos. Cidadania e justiça: a política social na ordem brasileira. 2. ed. São Paulo: Paulus, 1987.

TOUCHARD, Jean. (Coord.) História das idéias políticas. Lisboa: Europa-América, 1970. v.1.

WOLF, Francis. Nascimento da razão: origem da crise. In: NOVAES, Adauto (Org.) A crise da razão. São Paulo: Companhia das Letras, 1996. p. 67-82.

Recebido em 24.10.01

Aprovado em 08.07.02

Marlene Ribeiro é doutora em Educação; professora titular do PPGEDU/UFRGS; coordenadora do Núcleo em Trabalho, Movimentos Sociais e Educação. Autora de: Universidade Brasileira Pós-Moderna: democratização x competência. Manaus: EDUA, 1999; Trabalho Cooperativo no MST e ensino fundamental rural: desafios à educação básica. Revista Brasileira de Educação, São Paulo, n.17, p. 20-39, mai./ago. 2001. 